\title{
Review on Infections of the Central Nervous System by St. Louis Encephalitis, Rocio and West Nile Flaviviruses in Brazil, 2004-2014
}

\author{
Mario Luis Garcia de Figueiredo, Luiz Tadeu Moraes Figueiredo \\ Research Center for Virology, Faculty of Medicine of RibeirãoPreto, University of São Paulo, \\ São Paulo, Brazil \\ Email: marioluisgf@yahoo.com.br
}

Received 12 August 2014; revised 6 September 2014; accepted 2 October 2014

Copyright (C) 2014 by authors and Scientific Research Publishing Inc.

This work is licensed under the Creative Commons Attribution International License (CC BY). http://creativecommons.org/licenses/by/4.0/

(c) (i) Open Access

\section{Abstract}

Rocio (ROCV), Saint Louis encephalitis (SLEV) and West Nile (WNV) are Flavivirus (Flaviviridae) probably carried by birds and transmitted by Culex mosquitoes. We show here a review on infections of the central nervous system by St. Louis Encephalitis, Rocio and West Nile Flaviviruses in Brazil, 2004-2014. In the last 10 years, serologic surveys in horses showed high proportions of seropositive animals which point out that SLEV and ROCV have circulated infecting horses in westcentral, southeast and other regions of Brazil and that WNV has been introduced into Brazil and circulates mostly in Pantanal region. However humans infected by WNV have not been reported. In the State of São Paulo: SLEV was isolated from a case clinically diagnosed as dengue in 2004; in 2006, 6 SLEV patients including 3 cases of menigoencephalitis were reported in the middle of a large epidemic of dengue type 3; and in 2008, 1 patient with acute febrile illness that was IgMpositive for dengue was found infected by SLEV by detection of the virus genome. In 2010, ROCV genome was detected in the cerebrospinal fluids of 2 patients from the northern region with meningoenchephalitis and also AIDS. This was the first report of infections by ROCV in the last 34 years and curiously, it occured more than $2000 \mathrm{~km}$ from where the virus was firstly found. It is necessary to improve the surveillance of SLEV, ROCV and WNV in Brazil.

\section{Keywords}

Rocio Virus, Saint Louis Encephalitis Virus, West Nile Virus, Brazil

\section{Introduction}

Brazil is the largest country in South America. Located in the tropical area of the globe, the country has a large

How to cite this paper: de Figueiredo, M.L.G. and Figueiredo, L.T.M. (2014) Review on Infections of the Central Nervous System by St. Louis Encephalitis, Rocio and West Nile Flaviviruses in Brazil, 2004-2014. Advances in Microbiology, 4, 955961. http://dx.doi.org/10.4236/aim.2014.413106 
variety of flora and fauna that includes many arthropods, specially mosquitoes and midges. Thus, the country offers suitable condition for maintenance and emergence of new arboviral cycles. Therefore, some zoonotic arboviruses, like Oropouche, Mayaro, Rocio (ROCV), Saint Louis encephalitis (SLEV) and yellow fever virus, have been found producing human diseases and outbreaks. Besides, arboviruses present in other American countries, such as those emergent viruses West Nile (WNV) and Chikungunya, both have been recently introduced in the country. The Brazilian population of 200 million inhabitants is mostly concentrated in the southeastern, northeastern and southern regions that are infested by Aedesand Culex mosquitoes. Aedesaegypti transmits dengue in large epidemics with hundreds of thousands of reported patients including some severe and fatal cases. Cases of meningoencephalitis were also attributed to dengue virus in the country. In this context, public health authorities are very much interested on the control of this virus by performing the clinical and serological diagnosis of cases and also by the fight against Aedesaegypti. However, we highlight that while they focus only on dengue, other viruses of the same genera (Flavivirus) that produce acute febrile illness and meningoencephalitis can remain undetected.

The 50 species and 23 viral subtypes included in the Flavivirus genus of the Flaviviridae are further separated into 12 groups based on antigenic and ecological similarities as well as by phylogenetic analysis of the NS5 gene [1]. One of these groups is that of Japanese encephalitis (JE) serocomplexthat is globally distributed and include West Nile virus (WNV), Murray Valley encephalitis virus, St. Louis encephalitis virus (SLEV), and Japanese encephalitis virus (JEV). Other serocomplexes include the yellow fever virus (YFV), the tick-borne encephalitis (TBEV), and the Dengue (DENV). The viruses of the JE serocomplex are maintained in nature in a cycle involving mosquitoes and in most cases, birds as the vertebrate host. Horses and humans when infected are dead-end hosts because their viraemias are usually insufficient to subsequently infect feeding mosquitoes. Viruses of this complex are responsible for important diseases in humans mostly because they are neurotropic and cause meningoncephalitis [2]. The flaviviruses of JE serocomplex that have major medical importance in South American countries are SLEV, WNV and ROCV. These zoonotic viruses are probably carried by birds and transmitted by mosquitoes of the genus Culexsp [3].

\section{Serologic Surveys}

Serologic surveys are important tools to detect infections by arbovirus and to determine antibody levels to these agents. Serologic surveys to ROCV, SLEV and WNV have been performed in Brazilian horses. These large animals were choosen because they live outdoors and in close contact with humans. Horses are constantly sucked by mosquitoes and commonly become infected by multiple flaviviruses during their lifetimes. Similarly, wild primates that are phylogenetically close related to men and also domestic birds, possible arbovirus reservoirs, are suitable animals for serological surveys. In a study performed in southern Brazil, 2004-2005, infections by 20 arboviruses in nonhuman primates and horses were investigated. Neutralizing antibodies were only observed to SLEV. Specific antibodies to SLEV were detected in monkeys, Alouattacaraya (1 of 42), Sapajusnigritus (9 of 64) and Sapajus cay (4 of 26). In the same study, antibodies to SLEV were detected in 9 of 23 horse sera by inhibition hemmaglutination test [4]. A serologic survey to ROCV, SLEV and WNV has included sera from 753 healthy horses from Central-West, Northeast and Southeast Brazil. Sera were tested by enzyme immunosorbent assay (ELISA) using recombinant peptides from domain III of the envelope protein of ROCV, SLEV and WNV [5]. A proportion of 55\% of the 753 studied animals were seropositive to these viruses suggesting that infections by Flavivirus are common among equines. Monotypic reactions to SLEV were observed in 93 horses from MatoGrosso do Sul, Minas Gerais, Paraiba, Rio de Janeiro and São Paulo. Monotypic reactions to ROCV were observed in 46 animals from the same states with the only exception of Minas Gerais [6]. Aditionally, of 79 ELISA positive horses to WNV, 9 expressed WNV specific neutralising antibodies. Eight of these animals were from the Pantanal region in the state of MatoGrosso do Sul and 1 was from the state of Paraíba in the Northeast of the country [7]. Another serologic survey, performed in 2009, included 168 horses from Pantanal region showing neutralizing antibodies to SLEV in the sera of 9 animals and neutralizing antibodies to WNV in the sera of 5 animals [8]. The Brazilian Pantanal region is a huge swamp that releases the water through the Paraguay River and tributaries. Yearly, Pantanal has seasonal inundations and desiccations allowing suitable ecological condition for that 1000 bird species (including migratory animals), 400 fish species, 300 mammalian species, 480 reptile species and over 9000 different subspecies of invertebrates can live in the region [9]. In a recent study, sera from 760 equines of Pantanal region were analyzed by plaque reduction neutralization test 
(PRNT) for 12 flaviviruses showing that 59 of them were positive for SLEV, 24 for WNV, and 1 for ROCV. This study presents one more evidence of the circulation of these 3 viruses in the region [10]. Finally, neutralizing antibodies for WNV were reported in the sera of 4 horses, collected in 2009, in an area between the Amazon and the Pantanal regions [11]. In short, these serologic surveys point that it is strongly possible that SLEV and ROCV have circulated infecting horses in northeast, west-central and southeast Brazil. The results also provide additional evidence for the emergence of WNV in Brazil and for its circulation mostly in Pantanal region but also in other regions [4] [6]-[8] [10] [11]. Unfortunately, it was not possible to know on human diseases in order to correlate them to the animal infections by ROCV, SLEV and WNV. Human infection and disease by these viruses probably occur in the area but remain without diagnosis.

\section{St. Louis Encephalitis Virus (SLEV)}

SLEV is distributed in the Americas, from Canada to Argentina. SLEV was firstly isolated in Brazil in 1960 from a pool of Sabethesbelisarioi captured at the Belem-Brasília highway [12]. In the southern region, the virus was isolated from sentinel animals, rodents and a bird [13]. SLEV was also isolated from 2 Brazilian patients presenting a febrile illness with jaundice [13]. Serologic evidence of infection by SLEV have been observed in the Amazon region as well as in the eastern and southeastern regions of Brazil [13]. The SLEV cycle in the Amazon region include Culexdeclarator and Culexcoronator as vectors and wild birds, monkeys, sloths, armadillos and marsupials as virus reservoirs [14]. In the last 10 years human disease by SLEV has been reported in the southeastern region of Brazil. In 2004, SLEV was isolated from a case clinically diagnosed as dengue fever in the city of São Pedro [15]. In 2006, 8 patients with acute febrile illness, from the city of RibeirãoPreto, were seropositives to SLEV in a highly specific neutralization test (unpublished data). In the next year, 6 patients infected by SLEV were diagnosed by polymerase chain reaction preceded by reverse transcription (RT-PCR) right in the middle of a large epidemic of dengue type 3, in the city of São José do Rio Preto [16] [17]. Two SLEV patients had non-fatal menigoencephalitis. The other patients infected by SLEV had acute febrile dengue-like symptoms and also minor hemorrhagic manifestations (positive tourniquet test). However, it is difficult to explain the positive tourniquet test observed in patients infected by SLEV. Yet, it was also reported a case of coinfection by dengue type 3 and SLEV [18]. It is remarkable that this patient did not develop any severe clinical manifestations despite having double infection. In 2008, aspects of the laboratory diagnosis of a patient with acute febrile illness induced by SLEV were reported. The diagnosis was confirmed by RT-PCR followed by nucleotide sequencing of the amplicon. This patient was initially diagnosed as having dengue fever by positive IgMELISA [19]. The diagnosis of SLEV was only possible because rather than a dengue specific RT-PCR, the samples were tested by a multiplex-nested RT-PCR to detect and identify the main Brazilian arboviruses of genera Flavivirus and Alphavirus [20]. It is worrying that diseases by SLEV and other flaviviruses could be diagnosed as dengue based on positive IgMELISA. Thus, cross-reaction of antibodies could induce a wrong diagnosis of dengue.

SLEV shows a high genetic variability and geographical dispersion in the Americas. In 2010, it was reported a phylogenetic analysis based on full-length sequences of the envelope (E) protein of 30 Brazilian strains of SLEV. It was observed that genotype VIII was restricted to the northern Amazon region and genotype V was widely distributed in the Americas. Genotypes III and V were associated to the human cases reported in the last decade in the southeastern region of Brazil. Genotype III was also genetically related to strains isolated from Culexquinquefasciatus in Argentina in 2005. Moreover, it was suggested that SLEV emerged in South America and spread toward North America [21].

It is important for the control of SLEV, study the zoonotic cycle of the virus in urban areas of Brazil and particularly in the state of São Paulo by finding animal-reservoirs (birds? What species?) and mosquito-vectors (Culexpipiensfatigans?).

\section{Rocio Virus (ROCV)}

Until recently, ROCV have been found only in Ribeira valley at the southeastern region of Brazil, in the 1970s, when it produced an outbreak. During this epidemic, 1021 encephalitis cases were reported, approximately 100 deaths were observed, and more than 200 surviving patients presented sequelae [13]. ROCV disease of the central nervous system struck mostly young men after a 7 - 14-day incubation period. The patients presented fever, headache, anorexia, nausea, vomiting, myalgia and malaise. Later appeared signs of encephalitis, including con- 
fusion, reflex disturbances, motor impairment, meningeal irritation, cerebellar syndrome and seizures. Other symptoms included abdominal distension and urinary retention. ROCV encephalitis produced as sequelae: visual, olphactory, and auditory disturbances, lack of motor coordination, equilibrium disturbance, swallowing difficulties, incontinence and defective memory [22]. ROCV was isolated 3 times during this outbreak, from a patient, a Psorophoraferox mosquito and a wild migratory bird [23]. The epidemiology of ROCV practically remain unknown and causes for virus appearance and disappearance are a mystery. After this outbreak, serologic evidence of ROCV circulation has been reported in different regions of the country and public health authorities are concerned about a return of ROCV outbreaks in Brazil. In 2010, the genome of ROCV was amplified by RT-PCR from 2 cerebrospinal fluids of patients with non-fatal meningoenchephalitis (unpublished data). Virus identification was performed in both cases by sequencing nucleotides of the PCR products. Curiously, both patients had AIDS and this was the first report of infections by ROCV in the last 34 years. Moreover, these 2 cases appeared in the city of Manaus, North of Brazil, more than $2000 \mathrm{~km}$ from where the virus was firstly found.

In the last 10 years some Brazilian studies have been performed to better understand the infection and the invasion of the central nervous system by ROCV. It is known that after inoculation by mosquito bite, flaviviruses primarily infect blood monocytes and tissue macrophages, which have been shown to be permissive, supporting viral replication and serving as virus reservoirs. These cells also may have an important antiviral activity related to immune modulation by cytokine production and by the capacity of these cells to synthesize reactive free radicals. An in vitro study with murine macrophages infected by SLEV, ROCV and other flaviviruses has shown that SLEV reduced the production of IL- $1 \alpha$ and TGF- $\beta$ by LPS-stimulated macrophages, while ROCV only diminished LPS-stimulated TGF- $\beta$ synthesis. Additionally, while SLEV and ROCV have stimulated the production of IFN- $\gamma$, none of them has changed the production of TNF- $\alpha$ by murine macrophages. Interestingly, both viruses, SLEV and ROCV, have induced the synthesis of nitric oxide which is a free radical with microbicidal effect [24]. Another study used golden hamsters (Mesocricetusauratus) infected intraperitoneally with ROCV that were later sacrificed, at various days over 4 month period, to collect samples. It was found that the virus produces neuroinvasion in hamsters and also induces a strong immune response. ROCV was detected in the brain, liver and blood for three months after infection. Histopathological changes and expression of viral antigens were observed in liver, kidney, lung and brain up to 4 months after infection. These findings show that ROCV is able to cause persistent infection in golden hamsters after intraperitoneal inoculation [25].

In a study on the disease produced by ROCV in the central nervous system of Balb/C young adult mice, the animals were intraperitoneally infected and followed up from 0 thru 9 days after infection, when all of them had paralysis of hind paws and death. ROCV was detected in CNS 2 hours after infection and also produced a severe form of meningoencephalomyelitis. It was observed the viral infection of neurons, glial and endothelial cells. ROCV also induced inflamatory responses with increased production of TNF- $\alpha$, IL- $1 \beta$, IFN- $\gamma$ e IFN- $\alpha$, related to TH1 immune response, and TGF- $\beta$, IL-4and IL-10, related to TH2 immune response. Last, apoptosis and death of neurons was observed when the mice had severe encephalitis and died (9 days after infection) [26]. In another study, it was analyzed the CC-chemokine receptor 5 (CCR5) that binds to macrophage inflammatory protein (MIP) $1 \alpha \alpha v \delta w v \phi \lambda v \varepsilon v \chi \varepsilon$ the migration of these cells into mouse brains infected by ROCV. It was observed that CCR5 and MIP $1 \alpha$ knockout mice survived longer and with a reduced inflammation in the brain than wild-type ROCV-infected animals. Moreover the knockout mice required a higher lethal dose than those mice of the wild type. The CCR5/MIP-1 $\alpha$ axis may contribute to the migration of cells into ROCV infected brains [27]. These findings can help to better understand the pathogenesis and the physiopathology of the human meningoencephalomyelitis by ROCV and other flaviviruses of the JE serocomplex.

\section{West Nile Virus (WNV)}

WNV is a pathogen from Africa and Asia that emerged in North America in 1999 and spread toward practically all the Americas (North, Central and South). This virus is the causative of severe encephalitis in humans, birds, and in horses. In the North America, WNV has caused dozens of thousands of clinical cases and some thousands of deaths of humans and horses [28]. WNV was isolated in Argentina, 2006, from the brain of 3 horses [29]. Based on the virus introduction in Argentina as well as in the results of serologic surveys shown above, WNV has been introduced in Brazil and it is probably spreading in the country based on a transmission network that involves mosquitoes, birds and horses. However, human disease by WNV has not been reported in Brazil or in the whole South America. The absence of human cases could be related to a cross-immune protection of the 
Brazilian population that has an extensive contact with other flaviviruses (dengue, yellow fever vaccine, SLEV, etc.).

\section{Laboratory Diagnosis of SLE, ROC and WNV}

Considering that the sera of patients infected by SLEV or other flaviviruses, could cross-react with dengue by serology, including those tests that detect specific IgM, virology laboratories should use more than one method to confirm dengue diagnosis and also should develop diagnostic tests for several arboviruses that produce human disease, using these tests as a routine, inclusively, during dengue epidemics [19].

Laboratory diagnosis of Flavivirus includes their genome detections by RT-PCR. In most of the studies summarized here a Flavivirus (genus)—specific RT-PCR followed by species-specific M-N-PCR or N-PCR were used for identification of some of the common Brazilian Flavivirus (DENV 1-4, YFV, SLEV, Rocio and ilheus) [20]. However, the detection of viral RNA is reduced in low viremic infections at the time of clinical presentation in humans as well as in horses. The chance of detection of the viral RNA is also reduced in humans when the laboratory diagnosis is performed after 5 days of disease. Thus, in these cases the diagnosis is commonly achieved using serological assays such as enzyme-linked immunosorbent assay (ELISA). ELISAs are more used for serological screening than the more specific plaque reduction neutralization tests that are time consuming and require the handling of live virus. IgG-ELISAs are used for determination of antibody levels to Flavivirus in serologic surveys. For most of the serologic surveys summarized here, were used IgG-ELISAs including recombinant peptides of the domain III (rDIII) of envelope proteins of WNV, SLEV and ROCV. Previously, these rDIII antigens have been bacterially expressed and purified [5] [6] [30].

\section{Study on Vectors}

An study was performed to evaluate the capacity to suppress replication of pathogenic flaviviruses transmitted by Culex spp. Co-infection experiments indicated that prior or concurrent infection of mosquito cells with Nhumirin (NHUV, an mosquito-specific Flavivirus) have reduced significantly the viral production of WNV, SLEV and JEV. This inhibitory effect was more effective against WNV and SLEV reducing their titers over a millionfold and 10,000-fold respectively. This modulatory effect based on co-infections is a potential weapon for blocking the infection of the mosquito with medically important flaviviruses [31].

\section{Conclusion}

Finally, it is necessary to improve the surveillance of SLEV, ROCV, WNV in Brazil. Therefore, doctors must include flaviviruses (not only dengue) and other arboviruses in their differential diagnosis of acute febrile disease and of meningoencephalitis. In fact, if the doctors do not think on these pathogens, it will prevail the mistaken idea that their diseases do not exist here!

\section{Acknowledgements}

We greatefully acknowledge the national council of scientific and technological development CNPq for the post-doctorate grant.

\section{References}

[1] Lindenbach, B.D., Thiel, H.J. and Rice, C.M. (2011) Flaviviridae: The Viruses and Their Replication. In: Knipe, D.M. and Howley, O.M., Eds., Fields Virology, 5th Edition, Lippincot William \& Wilkins, Philadelphia, 1101-1151.

[2] Kuno, G., Chang, G.J.J., Tsuchiya, K.R., Karabatsos, N. and Cropp, C.B. (1998) Phylogeny of the Genus Flavivirus. Journal of Virology, 72, 73-83.

[3] Baleotti, F.G., Moreli, M.L. and Figueiredo, L.T.M. (2003) Brazilian Flavivirus Phylogeny Based on NS5. Memórias do Instituto Oswaldo Cruz, 98, 379-382. http://dx.doi.org/10.1590/S0074-02762003000300015

[4] Svoboda, W.K., Martins, L.C, Malanski, L.deS., Shiozawa, M.M., Spohr, K.A., Hilst, C.L., Aguiar, L.M., Ludwig, G., Passos, F.deC., Silva, L.R., Headley, S.A. and Navarro, I.T. (2014) Serological Evidence for Saint Louis Encephalitis Virus in Free-Ranging New World Monkeys and Horses within the Upper Paraná River Basin Region, Southern Brazil. Journal of the Brazilian Society of Tropical Medicine, 47, 280-286. 
[5] Chávez, J.H., Silva, J.R. and Figueiredo, L.T.M. (2013) Production and Diagnostic Application of a Recombinant Domain III of West Nile Envelope Protein. Journal of the Brazilian Society of Tropical Medicine, 46, 97-99. http://dx.doi.org/10.1590/0037-868214142013

[6] Silva, J.R., Romeiro, M.F., Sousa, W.M., Munhoz, T.D., Borges, G.P., Soares, O.A.B., Campos, C.H.C., Machado, R.Z., Silva, M.L.C.R., Faria, J.L.M., Chávez, J.H. and Figueiredo, L.T.M. (2014) Serosurvey of Saint Louis Encephalitis and Rocio Viruses in Horses of Brazil. Journal of the Brazilian Society of Tropical Medicine, 47, 414-417.

[7] Silva, J.R., Chávez, J.H., Munhoz, T.D., Borges, G.P., Soares, O.A.B., Machado, R.Z., Valadão, C.A.A., Silva, M.L.C.R., Faria, J.L.M., Silva, E.E. and Figueiredo, L.T.M. (2013) Serologic Survey for West Nile Virus in Brazilian Horses. Memories Institute OswaldoCruz, 108, 921-923.

[8] Pauvolid-Corrêa, A., Morales, M.A, Levis, S., Nogueira, R.M.R., Lima, D.C., Campos, Z., Figueiredo, L.T.M., Furlan, M.N., Silva, E.E. and Schatzmayr, H.G. (2011) Neutralizing Antibodies to West Nile Virus in Horses from South Pantanal, Brazil. Memories Institute OswaldoCruz, 106, 467-474.

[9] McClain, M.E. (2002) The Ecohydrology of South American Rivers and Wetlands. International Association of Hydrological Sciences (IAHS) AHS Press, Rennes.

[10] Pauvolid-Corrêa, A., Campos, Z., Juliano, R., Velez, J., Nogueira, R.M. and Komar, N. (2014) Serological Evidence of Widespread Circulation of West Nile Virus and Other Flaviviruses in Equines of the Pantanal, Brazil. PLoS Neglected Tropical Diseases, 8, e2706.

[11] Ometto, T., Durigon, E.L., de Araujo, J., Aprelon, R., de Aguiar, D.M., Cavalcante, G.T., Melo, R.M., Levi, J.E., de Azevedo, S.M., Petry, M.V., Neto, I.S., Serafini, P., Villalobos, E., Cunha, E.M., Lara, M., Nava, A.F., Nardi, M.S., Hurtado, R., Rodrigues, R., Sherer, A.L., Sherer, J.F., Geraldi, M.P., de Seixas, M.M., Peterka, C., Bandeira, D.S., Pradel, J., Vachiery, N., Labruna, M.B., de Camargo, L.M., Lanciotti, R., and Lefrançois, T. (2013) West Nile Virus Surveillance, Brazil, 2008-2010. Transactions of the Royal Society of Tropical Medicine and Hygiene, 107, 723-730.

[12] da Rosa, J.F.S.T., Freitas, E.M., da Rosa, A.P.A.T. and Pinheiro, F.P. (1980) Epidemiology of St. Louis Encephalitis in the Amazon, the FSESP Magazine 25 73-80 Virus.

[13] Figueiredo, L.T.M. (2000) The Brazilian Flaviviruses. Microbes and Infection, 2, 1643-1649. http://dx.doi.org/10.1016/S1286-4579(00)01320-4

[14] da Rosa, J.F.S.T., da Rosa, A.P.A.T., Vasconcelos, P.F.C., Rodrigues, S.G., da Rosa, E.S.T., Dias, L.B. and Cruzi, A. C.R. (1998) Arboviruses Isolated in the Evandro Chagas Institute, Including Some Described for the First Time in the Brazilian Amazon Region, Their Known Hosts, and Their Pathology for Man. In: da Rosa, A.P.A.T., Vasconcelos, P.F. C. and da Rosa, J.F.S.T., (Eds.), An Overview of Arbovirology on Brazil and Neighboring Countries, Instituto Evandro Chagas, Belem, 19-31.

[15] Rocco, I.M., Santos, C.L., Bisordi, I., Petrella, S.M., Pereira, L.E., Souza, R.P., Coimbra, T.L., Bessa, T.A., Oshiro, F. M., Lima, L.B., Cerroni, M.P., Marti, A.T., Barbosa, V.M., Katz, G. and Suzuki, A. (2005) St. Louis Encephalitis Virus: First Isolation from a Human in São Paulo State, Brazil. Revista do Instituto de Medicina Tropical de São Paulo, 47, 281-285. http://dx.doi.org/10.1590/S0036-46652005000500008

[16] Mondini, A., Lázaro, E., Cardeal, I.L.S., Nunes, S.H., Moreira, C.C., Rahal, P., Figueiredo, L.T.M., Bronzoni, R.V.M., Neto, F.C. and Nogueira, M.L. (2007) Saint Louis Encephalitis Virus, Brazil. Emerging Infectious Diseases, 13, $176-$ 178. http://dx.doi.org/10.3201/eid1301.060905

[17] Terzian, A.C.B., Mondini, A., Bronzoni, R.V.M., Drumond, B.P., Ferro, B.P., Cabrera, E.M.S., Figueiredo, L.T.M., Neto, F.C. and Nogueira, M.L. (2011) Detection of Saint Louis Encephalitis Virus in Dengue-Suspected Cases during a Dengue 3 Outbreak. Vector-Borne and Zoonotic Diseases, 11, 291-300. http://dx.doi.org/10.1089/vbz.2009.0200

[18] Mondini, A., Bronzoni, R.V.M., Cardeal, I.L.S., Santos, T.M.I.L., Lázaro, E., Nunes, S.H.P., Silva, G.C.D., Madrid, M. C.F.S., Rahal, P., Figueiredo, L.T.M., Neto, F.C. and Nogueira, M.L. (2007) Simultaneous Infection by DENV-3 and SLEV in Brazil. Journal of Clinical Virology, 40, 84-86. http://dx.doi.org/10.1016/j.jcv.2007.06.007

[19] Maia, F.G.M., Chávez, J.H., Souza, W.M., Romeiro, M.F., Castro, L.A., da Fonseca, B.A.L. and Figueiredo, L.T.M. (2014) Infection with Saint Louis Encephalitis Virus in the City of Ribeirao Preto, Brazil: Report of One Case. International Journal of Infectious Diseases, 26, e96-e97. http://dx.doi.org/10.1016/j.ijid.2014.05.018

[20] Bronzoni, R.V.M., Nogueira, R.M.R., Nunes, M., and Figueiredo, L.T.M. (2005) Detection and Identification of Brazilian Alphaviruses and Flaviviruses by Multiplex RT-PCR. Journal of Clinical Microbiology, 43, 696-702. http://dx.doi.org/10.1128/JCM.43.2.696-702.2005

[21] Rodrigues, S.G., Nunes, M.R., Casseb, S.M., Prazeres, A.S., Rodrigues, D.S., Silva, M.O., Cruz, A.C., Tavares-Neto, J.C. and Vasconcelos, P.F. (2010) Molecular Epidemiology of Saint Louis Encephalitis Virus in the Brazilian Amazon: Genetic Divergence and Dispersal. Journal of General Virology, 91, 2420-2427.

[22] Tiriba, A.C., Miziara, A.M., Lourenço, R., Costa, C.R.B., Cota, C.S. and Pinto, G.H. (1976) Primary Human Arbovirus Encephalitis Epidemic Observed for the South Coast of São Paulo. J. Assoc. Med. Bras., 22, 415-420. 
[23] Lopes, O.S., Coimbra, T.L.M., Sacchetta, L.A. and Calisher, C.H. (1978) Emergence of a New Arbovirus Disease in Brazil. I. Isolation and Characterization of the Etiologic Agent, Rocio Virus. American Journal of Epidemiology, 107, 444-449.

[24] Barros, V.E.D., Ferreira, B.R., Livonesi, M.C. and Figueiredo, L.T.M. (2009) Cytokine and Nitric Oxide Production by Mouse Macrophages Infected with Brazilian Flaviviruses. Revista do Instituto de Medicina Tropical de São Paulo, 51, 141-147. http://dx.doi.org/10.1590/S0036-46652009000300004

[25] Henriques, D.F., Quaresma, J.A., Fuzii, H.T., Nunes, M.R., Silva, E.V., Carvalho, V.L., Martins, L.C., Casseb, S.M., Chiang, J.O. and Vasconcelos, P.F. (2012) Persistence of Experimental Rociovirus Infection in the Golden Hamster (Mesocricetus auratus). Memórias do Instituto Oswaldo Cruz, 107, 630-636.

[26] de Barros, V.D., Penharvel, S., Forjaz, J., Saggioro, F.P., Neder, L., Figueiredo, L.T.M., et al. (2011) An Experimental Model of Meningoencephalomyelitis by Rocio Virus in Balb/C Mice: Hystopathology, Inflammatory Response and Cytokine Production. American Journal of Tropical Medicine and Hygiene, 85, 363-373. http://dx.doi.org/10.4269/ajtmh.2011.10-0246

[27] Chávez, J.H., França, R.F.O., Oliveira, C.J., Aquino, M.T.P., Farias, K.J., Machado, P.R., Yokosawa, J., Silva, J.S., da Fonseca, B.A.L. and Figueiredo, L.T.M. (2013) CCR-5/MIP-1 $\alpha$ Affect the Pathogenesis of Rocio Virus Encephalitis in a Mouse Model. American Journal of Tropical Medicine and Hygiene, 89, 1013-1018. http://dx.doi.org/10.4269/ajtmh.12-0591

[28] Petersen, L.R. and Hayes, E.B. (2008) West Nile Virus in the Americas. Medical Clinics of North America, 92, 13071322. http://dx.doi.org/10.1016/j.mcna.2008.07.004

[29] Morales, M.A., Barrandeguy, M., Fabbri, C., Garcia, J.B., Vissani, A., Trono, K., Gutierrez, G., Pigretti, S., Menchaca, H., Garrido, N., Taylor, N., Fernandez, F., Levis, S. and Enría, D. (2006) West Nile Virus Isolation from Equines in Argentina, 2006. Emerging Infectious Disease, 12, 1559-1561. http://dx.doi.org/10.3201/eid1210.060852

[30] Chávez, J.H., Silva, J.R., Amarilla A.A. and Figueiredo L.T.M. (2010) Domain III Peptides from Flavivirus Envelope Are Useful Antigens for Serologic Diagnosis and Targets for Immunization. Biologicals, 38, 631-638. http://dx.doi.org/10.1016/j.biologicals.2010.07.004

[31] Kenney, J.L., Solberg, O.D., Langevin, S.A. and Brault, A.C. (2014) Characterization of a Novel Insect-Specific Flavivirus from Brazil: Potential for Inhibition of Infection of Arthropod Cells with Medically Important Flaviviruses. Journal of General Virology, Epub Ahead of Print. 
Scientific Research Publishing (SCIRP) is one of the largest Open Access journal publishers. It is currently publishing more than 200 open access, online, peer-reviewed journals covering a wide range of academic disciplines. SCIRP serves the worldwide academic communities and contributes to the progress and application of science with its publication.

Other selected journals from SCIRP are listed as below. Submit your manuscript to us via either submit@scirp.org or Online Submission Portal.
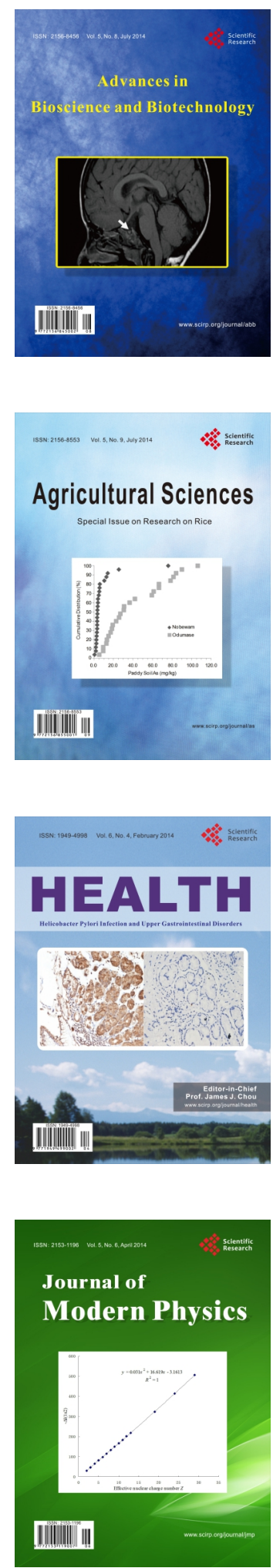
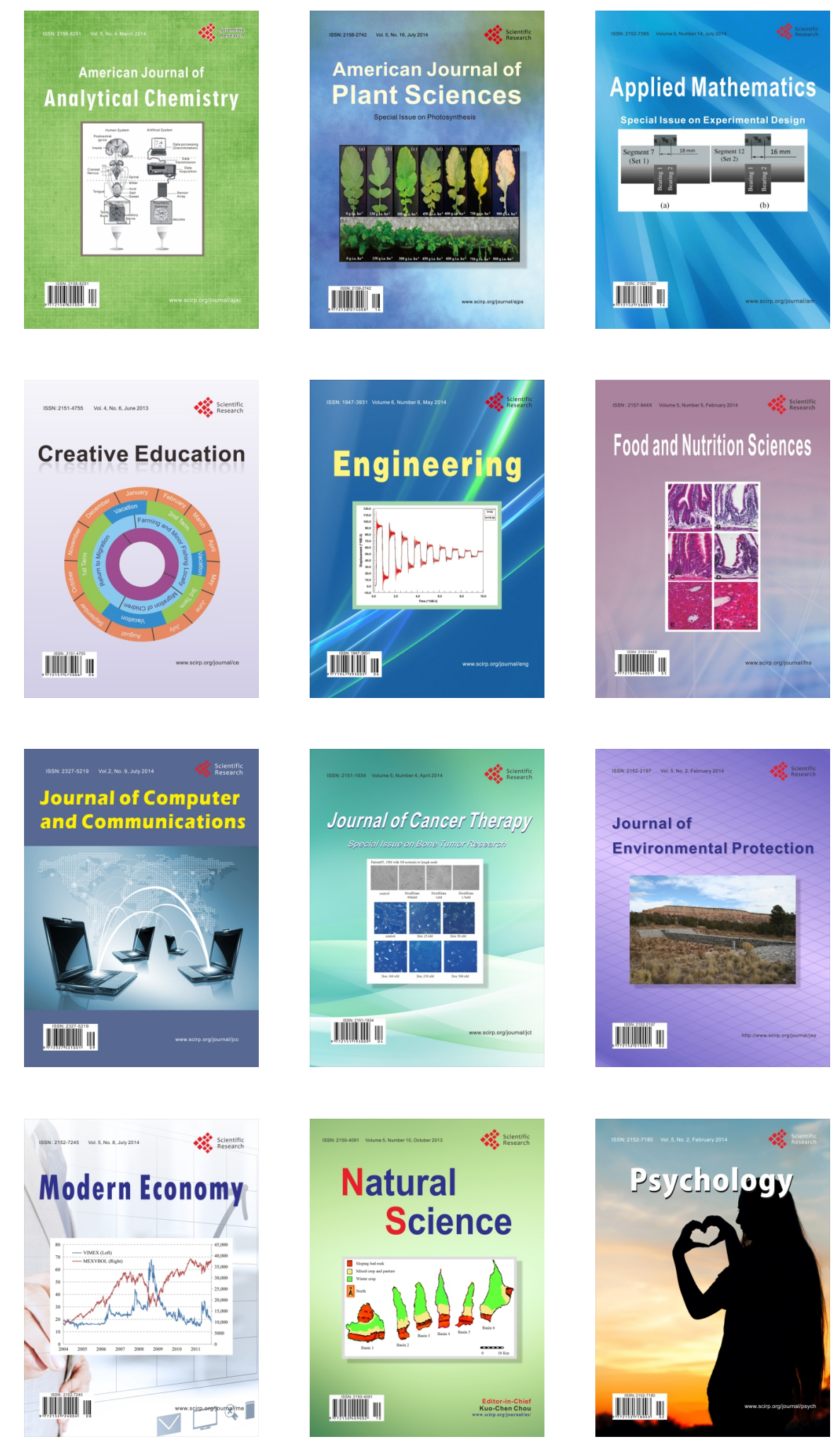